Methods A prospective observational study was performed using a repeated measures design in children from 3-17 years in two intensive care and high-dependency units in Ireland. Interrater reliability was tested among nurses using linearly weighted kappa, Cronbach $\alpha$ was applied to test internal consistency of the COMFORT-B scale and concurrent validity involved comparing COMFORT-B with the FLACC and Numeric Rating Scale score of nurses.

69 paired nursing assessments to test the interrater-reliability of the COMFORT-B scale was performed. With a high interrater-reliability of Cronbach 0.87 , Single nurse observations were commenced of the COMFORT-B, NRS and FLACC/Selfreport scores at specific four-hourly intervals over the first $48 \mathrm{~h}$ of each admission.

Results Data in 19 patients (age 3 to 17 years) was collected for the pilot study. Initial compliance of $4 \%$ increased to over $80 \%$. Interrater reliability between COMFORT, FLACC and NRS remained high throughout the study.

Conclusion The COMFORT-B is suitable for use in children and adolescents from 3-17years.

\section{P0-0867 WITHDRAWN}

\section{Nursing - Neonatal Brain and Development}

PO-0868 NEUROMONITORING; HOW TO TRAIN YOUR NURSING
STAFF

J Zoet-Lavooi, LGM van Rooij, AJ Brouwer, P Lemmers, LS de Vries. Neonatology, Wilhelmina Children's Hospital University Medical Center Utrecht, Utrecht, Netherlands

\subsection{6/archdischild-2014-307384.1492}

Background and aims Neuromonitoring, using amplitude-integrated Electroencephalography (aEEG) and near infra-red spectroscopy (NIRS), is common practice on our Neonatal Intensive Care Unit (NICU). The quality of the registration depends on the application of the aEEG-needles or hydrogel electrodes and the NIRS-pad, handling the equipment and interpretation of the registration.

Incorrect placement of the electrodes (too close to each other) by untrained nursing staff can lead to a registration full of artefacts, which may be interpreted as epileptic events or epileptic events may be missed. The correct interpretation of the aEEG patterns has a complex learning curve.

Method An e-learning course about monitoring the neonatal brain was developed to ensure that nurses are able to learn at any time, at any place on any computer. The hospital provided an e-learningteam. The e-learning course is located at a virtual learning environment which every member of the hospital staff has access to.

Results We developed an e-learning course which provides an interactive teaching tool to learn all about the near infra-red spectroscopy (NIRS) and four different aEEG monitor devices. Quizzes are included to practice how to interpret the aEEG recordings, which is essential in evaluating the monitoring of the neonatal brain.

Conclusion E-learning is an interactive learning tool which will enable the staff to keep their skills up to date in using different NIRS- and aEEG monitors and will allow correct interpretation of the aEEG recordings.

Acknowledgements Onbegrensd Leren (Learning without borders) UMC Utrecht.

\section{Nursing - Neonatal Pulmonology}

\section{PO-0869 DEVELOPMENT AND IMPLEMENTATION OF EVIDENCE BASED CLINICAL GUIDELINE REGARDING ENDOTRACHEAL SUCTIONING OF THE INTUBATED NEONATE}

${ }^{1} \mathrm{C}$ Riiser, ${ }^{2} \mathrm{RL}$ Stenkjær, ${ }^{3} \mathrm{~S}$ Nystrand. ${ }^{1}$ Neonatal Unit, University Hospital of Copenhagen, Dragør, Denmark; ${ }^{2}$ Neonatal Unit, University Hospital of Copenhagen, Kastrup, Denmark; ${ }^{3}$ Neonatal Unit, University Hospital of Copenhagen, Maaløv, Denmark

\subsection{6/archdischild-2014-307384.1493}

There is sparse evidence regarding endotracheal suctioning procedures in neonatal intensive care. We undertook a systematic literature review on following topics:

1. Suctioning frequencies

2. Pre-oxygenation

3. Installation of normal saline

4. Catheter size

5. Suctioning depth

6. Suctioning strength

7. In-line suctioning versus open suctioning

8. Recruitment manoeuvres

Results showed some evidence that suctioning could safely be performed as rarely as every eight hours plus as needed, that catheter size should not be larger than $70 \%$ of internal diameter of endotracheal tube size, that catheter only should be inserted as far as the tip of the tube, and that closed in-line suctioning systems could be used, and might be beneficial in neonates.

There is to sparse evidence regarding pre-oxygenation, installation af saline, strength of vacuum and recruitment manoeuvres to give evidence based recommendation.

The Neonatal unit in University Hospital of Copenhagen then changed suctioning guidelines accordingly to the recommendations found in the literature review.

We planned an implementation strategy inspired by Berwick and Bataldan's 'The Breakthrough Series', and Rogers 'Diffusion of Innovations', starting with baseline monitoring of chosen indicators such as incidence of occlusion of tubes, re-intubations, days on ventilator, length of stay, incidence of VAP, morbidity and mortality.

The implementation process was and is monitored by visual charts, graphs and numbers of the chosen indicators, and is a interdisciplinary focus in the unit.

\section{Nursing - Primary Care and General Paediatrics}

\section{PO-0870 THE SEXUAL DEVELOPMENT AND EDUCATION OF PRESCHOOL CHILDREN: KNOWLEDGE AND OPINIONS FROM DOCTORS AND NURSES}

${ }^{1} \mathrm{M}$ Kurtuncu, ${ }^{2} \mathrm{~L}$ Utas Akahn, ${ }^{3} \mathrm{I}$ Tanir, ${ }^{4} \mathrm{H}$ Yildiz. ${ }^{1}$ Pediatric Nursing, Bulent Ecevit University, Zonguldak, Turkey; ${ }^{2}$ Psychiatric Nursing, Bulent Ecevit University, Zonguldak, Turkey; ${ }^{3}$ Medical Doctor, Sultanbeyli State Hospital, Istanbul, Turkey; ${ }^{4}$ Nursing, Uludag University, Bursa, Turkey

\subsection{6/archdischild-2014-307384.1494}

Background and aims Especially the period between the ages of 0-6, which is known as the early childhood period (preschool period), is a very critical period where learning is fastest, the child is affected the most from environmental factors, and the 


\begin{tabular}{|c|c|c|c|}
\hline Socio-demographic Characteristics & & & Level of significance \\
\hline & & & $\mathrm{U}=2787.50$ \\
\hline & Female & $33.57 \pm 5.66$ & $Z=-0.782$ \\
\hline \multirow[t]{4}{*}{ Gender } & Male & $32.50 \pm 5.74$ & $p=0.434$ \\
\hline & 25 ve? & $27.00 \pm 3.55$ & \\
\hline & $26-30$ years & $32.34 \pm 5.79$ & \\
\hline & $31-35$ years & $34.85 \pm 5.88$ & $K W=12.000$ \\
\hline \multirow[t]{3}{*}{ Age group } & 36 ve? & $33.11 \pm 5.40$ & $p=0.007$ \\
\hline & Married & $33.58 \pm 5.70$ & \\
\hline & Single & $30.30 \pm 5.05$ & $\mathrm{KW}=11.02$ \\
\hline \multirow[t]{3}{*}{ Marital status } & Divorced & $37.75 \pm 2.62$ & $p=0.004$ \\
\hline & Nuclear family & $32.80 \pm 5.81$ & \\
\hline & Extended family & $34.60 \pm 4.87$ & $K W=5.159$ \\
\hline \multirow[t]{3}{*}{ Family type } & Single parent & $37.75 \pm 2.62$ & $p=0.076$ \\
\hline & & & $\mathrm{U}=1330.50$ \\
\hline & Yes & $33.85 \pm 5.51$ & $Z=-2.866$ \\
\hline \multirow[t]{4}{*}{ Do you have children? } & No & $30.25 \pm 5.62$ & $p=0.004$ \\
\hline & 1 & $33.57 \pm 6.05$ & \\
\hline & 2 & $33.86 \pm 5.54$ & \\
\hline & 3 & $35.40 \pm 3.93$ & $\mathrm{KW}=4.641$ \\
\hline \multirow[t]{4}{*}{ Number of children $(n=128)$} & 4 and more & $28.75 \pm 2.75$ & $p=0.200$ \\
\hline & Vocational school of health & $27.41 \pm 4.94$ & \\
\hline & Associate of science & $30.60 \pm 5.58$ & $\mathrm{U}=2094.50$ \\
\hline & Bachelor's degree & $35.83 \pm 4.30$ & $Z=-2.796$ \\
\hline Educational status & Other & $28.27 \pm 4.46$ & $p=0.005$ \\
\hline
\end{tabular}

chance for keeping the acquired attitudes, behaviour and habits in the following years is the highest. As in many subjects, giving the importance to sexual education in this period has many benefits regarding development. This descriptive study was carried out in order to determine knowledge levels and attitudes of doctors and nurses regarding children's sexual development and sex education.

Methods The design of the study is descriptive. The study was conducted with doctors and nurses who work at various clinics of two state hospitals located in the Istanbul province. A total of 138 doctors and 150 nurses work at these hospitals.

Results It was determined that the majority of cases were female and were aged more than 36 years. $63.5 \%$ of the cases have bachelor's degrees and $62.1 \%$ were medical doctors. It was determined that the number of correct responses given by the cases regarding some behaviours observed in children aged between 3-6 years and children's sexual development and sex education showed significant differences according to age group, marital status, status of having children, educational status, and occupation (Table 1).

Conclusions All of our cases think that it is necessary to provide sex education for children and the majority of cases think that sex education should be provided for children aged between 712 years.

\section{P0-0871 DISCHARGE MANAGEMENT MORE EFFECTIVE WHEN PARENTS PARTICIPATE}

${ }^{1} \mathrm{CJ}$ van der Perk, ${ }^{1} \mathrm{MGE}$ Jansen, ${ }^{2} \mathrm{MM}$ Maaskant, ${ }^{2} \mathrm{MI}$ van der Boon, ${ }^{2} \mathrm{E}$ Mout. ${ }^{1}$ Chirurgie and Zuigelingen H7Zuid, Academic Medical Center Women's and Children's Clinic, Amsterdam, Netherlands; 'Women's and Children's Clinic, Academic Medical Center, Amsterdam, Netherlands
Introduction Parents whose child is admitted in a hospital are often overwhelmed by an oncoming discharge. Especially when care has to be continued at home, parents instructions are provided only shortly before discharge. As a result discharge may be suboptimal or hospitalisation may be prolonged. The question arises whether family centred care contributes to a more effective and efficient discharge management.

Method We studied the literature, organised 4 focus group discussions with 21 nurses in total, and distributed a survey among 15 parent couples.

Results Results from several studies show that parents' participation reduces the time of hospitalisation by circa 3 days. In the focus group discussions nurses recognised that the moment of discharge is mainly based on medical criteria. As a result parents instructions start at a late moment, must be performed in a short period of time and sometimes increases the length of stay. The surveys showed that all parents feel responsible for the care of their child during hospitalisation. Of the parents, 64\% mentioned that they are involved in the discharge planning, that started at admission. However, only 34\% of the parents stated to be informed about discharge criteria.

Conclusion Parents' participation shortens the length of stay in hospital. However, the present discharge procedure is not sufficiently family centred and oncoming discharge is not discussed timely. We recommend to discuss discharge planning on a daily base within the team of care providers including the parents, and to involve parents in the discharge manangement.

\section{PO-0872 CASE MANAGEMENT IN PAEDIATRIC PALLIATIVE CARE}

A van der Tempel, AP Groenenberg, S Vallianatos. Women's and Children's Clinic, Academic Medical Center, Amsterdam, Netherlands 